\title{
Türkiye'de Gelir Dağılımı, Sağlık Harcamaları ve Yaşam Beklentisi İlişkisi: ARDL Sınır Testi Analizi
}

\author{
Ergül HALİSÇELİK ${ }^{1}$ \\ Ali ACARAVCI ${ }^{2}$ \\ Arif Eser GÜZEL ${ }^{3}$
}

ÖZ: Bu çalışma, Türkiye'de gelir dă̆glımı ve sağlık harcamalarının doğumda yaşam beklentisi üzerindeki etkilerini 1987-2016 dönemi için gecikmesi dağıtılmış otoregresif (ARDL) modeli ile araştırmaktadır. Elde edilen sonuçlara göre gelir dağılımında adaletsizlik arttıkça doğumda yaşam beklentisi negatif yönde etkilenmektedir. Öte yandan toplam sağlık harcamalarının milli gelir içindeki payının artması ile yaşam beklentisi arasında anlamlı bir ilişkiye bulunmamaktadır. Ayrıca kişi başına gelir ve her 1000 kişi başına doktor sayısının artması, yaşam beklentisini pozitif yönde etkilemektedir. Bu sonuçlar çerçevesinde, nitelikli sağlık personeli sayısının, ekonomik büyümenin ve yoksul kesimin refahının artmasının, daha sağllklı bir toplum hedefine ulaşmada önemli birer araç olduğu görülmektedir.

Anahtar Kelimeler: Gelir eşitsizliği, yaşam beklentisi, sağlık harcamaları Jel Kodları: I14, I15, I31

\section{Income Distribution, Health Expenditure and Life Expectancy Nexus in Turkey: ARDL Bounds Testing Analysis}

\begin{abstract}
This study investigates the effects of income distribution and health expenditure on life expectancy at birth in Turkey for the period 1987-2016 by using the autoregressive distributed lag (ARDL) bounds test approach to cointegration. According to results, rising income inequality effects life expectancy negatively. On the other hand, no significant relationship exists between health expenditure share of GDP and life expectancy. In addition, per capita income and number of physicians per 1000 people have positive impact on life expectancy. Within the framework of these results, it is seen that the increase in the number of qualified healthcare workers, economic growth and the welfare of the poor are important instruments for achieving the goal of a healthier society.
\end{abstract}

Keywords: Income inequality, life expectancy, health expenditure Jel Codes: I14, I15, I31

\footnotetext{
${ }^{1}$ Dr., T.C. Hazine ve Maliye Bakanlığı, Hazine Başkontrolörü, ehcelik@ gmail.com, orcid.or/ 00000003-2693-594X

${ }^{2}$ Prof. Dr., Hatay Mustafa Kemal Üniversitesi, İktisadi ve İdari Bilimler Fakültesi, İktisat Bölümü, acaravci@hotmail.com, orcid.org/0000-0002-6662-6175

${ }^{3}$ Arş. Gör., Hatay Mustafa Kemal Üniversitesi, İktisadi ve İdari Bilimler Fakültesi, İktisat Bölümü, arifeserguzel@mku.edu.tr, orcid.org/0000-0001-5072-9527
} 


\section{Giriș}

Kalkınma olgusu, uzun yıllardır iktisat yazının önemli araştırma konularından biri olmuştur. $\mathrm{Bu}$ alanda yapılan çalışmaların çoğunda, gelir odaklı bir yaklaşım kullanılmaktadır. Ancak kalkınma kavramı, iktisadi, sosyal, siyasi ve kültürel birçok faktördeki iyileşmeleri içinde barındırmakta; bu nedenle, insanların yaşam kalitesini artıran her olgu, bu kavram içerisinde değerlendirilmektedir. Bireylerin ve toplumun sağlı koşulları, kalkınma kavramının içerinde önemli bir yere sahiptir. Kalkınma eğer daha iyi bir yaşam standardını ifade ediyorsa, yaşamın kendisi de kalkınma kavramının içerisinde yer almalıdır. Gelişmiş bir toplumun en önemli göstergesi, uzun ve sağlıklı yaşayan bireylerdir.

Sağlık, kalkınma göstergelerinden biri olmanın yanı sıra ekonomik gelişme için gerekli olan beşeri sermaye oluşumunun da belirleyicilerindendir (Well, 2007). Gelişmiş ülkelerde yaşayan bireyler, az gelişmiş ülkelerde yaşayan bireylere kıyasla daha sağlıklı bir yaşam sürmektedir. Sen (1999)'a göre ülkelerin gelişmişlik düzeyleri arasındaki farklılıklar, sağlık koşullarını belirlemekte; toplum sağlığının iyileşmesi de ekonomik gelişmişliğin önünü açmaktadır. Sağlıklı insanların daha yüksek gelir elde etme imkânları, sağlıksız olanlara kıyasla daha yüksektir. Daha yüksek gelir elde eden bireyler ise daha iyi beslenme ve sağlik hizmetlerine erişim gibi imkânlardan faydalanabilmektedirler. Dolayısıyla ekonomik gelişmişlik ve sağlık koşullarının iyileşmesi, birbirini besleyen bir süreci ifade etmektedir. Bu bağlamda, daha sağlıklı bir toplum hedefine ulaşmayı sağlayacak değişkenlerin belirlenmesi, özellikle gelişmekte olan ülkeler ile gelişmiş ülkeler arasındaki ekonomik farklılıkların açıklanması noktasında son derece önemlidir. Ekonomik ilerleme ve sağlık arasındaki bu güçlü bağlantılar, politika yapıcıların kaynak tahsisi üzerindeki etkinliklerine bağl1 olarak değișebilmektedir (Sen, 1999: 623). $\mathrm{Bu}$ durum, ekonomik büyümenin yarattığı ilave kaynakların kamu sağlık hizmetlerine ve yoksulluğun azaltılmasına hangi oranda tahsis edildiğine bağlı olarak değişkenlik gösterebilecektir. Ekonomik gelişme aracılığ beklenen sağlık başarısı, ekonomik büyüme oranındaki artışın yanında bu artıştan toplumun yoksul kesiminin aldığı pay ile doğru orantılı olacaktır.

$\mathrm{Bu}$ çalışmanın amacı gelir dağılımındaki eşitsizliğin ve sağlık harcamalarının Türkiye'nin doğumda yaşam beklentisi üzerindeki etkilerini ampirik olarak araştırmaktır. Sağlık bir toplum hedefine ulaşmada, uygulamada ülkeden ülkeye farklılıklar görülmektedir. Bu nedenle sağlık politikalarının etkinliği araștırılırken ülkelere özgü analizler yapılması önem taşımaktadır. Bu çalışma ile Türkiye ve benzeri gelişmekte olan ülkeler için ilgili literatüre katkı sağlanması hedeflenmektedir.

\section{Literatür}

Bireylerin gelir düzeyi, yaşam standardının en önemli belirleyicisi olarak görülmektedir. Gelir düzeyinin yükselmesi ile beraber kişilerin, temel ihtiyaçlarını karşılayabilecek finansal kaynaklara ulaşımının önü açılmış olacaktır (Saunders, 
1996: 90). Dolayısıyla kişi başına gelir seviyesi yüksek ülkelerde yaşayan bireylerin daha yüksek refah düzeyine sahip olmaları ve yaşam sürelerinin uzun olmaları beklenmektedir (Judge, 1995: 1282). Sağlık söz konusu olduğunda da tek başına bireysel refahın yüksekliği yeterli olmamaktadır. Gelir düzeyi ne kadar yükselirse yükselsin bireyler, içinde yaşadıkları toplumdan tamamen izole bir hayat yaşamamaktadır. Dolayısıyla bireysel anlamda sağlık koşulları iyi olsa da sağlıksız bir toplumla bir arada yaşamak, kişisel gelir artışının yarattığı refah etkilerinin ortaya çıkmasını güçleştirecektir. Bireylerin uzun ve sağlıklı bir yaşam sürmeleri, içinde yaşadıkları toplumun sağlıklı olması ile mümkündür. Aynı zamanda, kişisel refahın artmasının yaşam beklentisini sürekli olarak artırması mümkün değildir. Her şeyden önce insan ömrü sınırlıdır ve doğumda yaşam beklentisinin bir limiti vardır. $\mathrm{Bu}$ düşünceden yola çıkarak Preston (1975), kişi başına gelir ile yaşam beklentisi ilişkisinin doğrusal olmadığına dikkat çekmiştir. Gelir düzeyinin yükseldiği ilk aşamalarda yaşam beklentisi hızla artarken bireyler zenginleştikçe yaşam beklentilerinin artış hızı düşecektir. Gelir artışı, yoksulları kötü sağlık koşullarından, sağlıksız çalışma ortamlarından, yetersiz beslenmeden ve bulaşıcı hastalıklardan korurken, bu sorunları çoktan aşmış olan zenginler için daha fazla gelir artışı, yoksul kesim ile aynı hızda bir yaşam beklentisi artışı yaratmayacaktır (Deaton, 2003: 1). Bu nedenle gelir dağılımının toplumun yoksul kesiminin lehine değişmesi, toplumun geneli için ortalama yaşam beklentisinin daha hızlı artmasını sağlayacaktır. Toplum sağlı̆̆ının iyileşmesi ve sağlık hizmetlerine ulaşımın önünün açılması için yoksul kesimin milli gelirden aldığ 1 payın artması gerekmektedir. Zengin ile yoksul arasındaki gelir farklılığının göreli daha düşük olduğu ülkelerde beklenen yaşam süresinin daha yüksek olduğu görülmektedir (Wilkinson, 1992: 1083). Deaton (2003)'a göre daha adil bir gelir dağılımına sahip toplumlarda sosyal dayanışma ve bütünlük daha yüksek iken stres daha azdır ve bu toplumlarda sosyal sermaye daha yüksektir.

Diğer yandan politika yapıcılar, kamu sağlık harcamalarının artırılması yoluyla toplum sağlığını iyileştirmeyi hedeflemektedirler. Ancak ülkelerin uyguladıkları sağlık sistemi, sağlık harcamalarının doğru alanlara yapılması ve toplumun bilinç düzeyi gibi faktörlerden dolayı, yapılan harcamalar beklenen hedeflere ulaşmayabilmektedir. Ayrıca sağlık harcamaları yapılırken öncelik verilen alanlar, teknolojik imkânlar ve kullanılan ilaçların ve makinelerin kalitesi ile yetişmiş tıbbi personelin niteliği, sağllkla ilgili girdilerin etkinliği üzerinde farklılaşmalar yaratabilmektedir (Çelik, 2011: 78). Bu nedenle yoksul kesimin refahının artmasının devlet eliyle yapılacak sağlık harcamalarından toplumun yaşam kalitesinin iyileştirilmesi bağlamında daha etkin olduğu düşünülmektedir.

Konuyla ilgili geçmiş çalışmalara bakıldığında ağırlıklı olarak ekonomik büyüme ve sağlık harcamalarının yaşam beklentisi üzerindeki etkilerinin araştırıldığı ve gelir dağılımına ilişkin ampirik çalışmaların kısıtlı olduğu görülmektedir.

Rodgers (1979), 56 ülkeye ait yatay kesit verileri ile gelir dağılımındaki değişimlerin yaşam beklentisi ve bebek ölümleri üzerindeki etkilerini araştırmıştır. 
Regresyon analizi sonuçlarına göre, Gini katsayısındaki artışlar yaşam beklentisini negatif yönde etkilerken bebek ölümlerini pozitif yönde etkilemektedir. Çalışmada daha adaletsiz bir gelir dağılımının toplum sağlığını olumsuz etkilediği sonucuna varılmıştır.

Gelir eşitsizliği ve yaşam beklentisi ilişkisini araştıran en önemli çalışmalardan biri Wilkinson (1992)'ın çalışmasıdır. Yazar, 9 gelişmiş ülkenin farklı dönemlere ait yatay kesit verileri ile yaptığı analizde gelişmiş ülkelerde artan gelir eşitsizliğinin yaşam beklentisini azalttığı sonucuna varmıştır.

Kawachi vd. (1997) çalışmalarında gelir eşitsizliği ile ölüm oranları arasındaki ilişkiyi Amerika Birleşik Devletleri'nin 39 eyaleti için araştırmışlardır. Çalışmada 1990 yılına ait veri seti kullanılmıştır. Yatay kesit regresyon analizi sonuçlarına göre, gelir eşitsizliğinin artması ve sosyal sermaye yatırımlarının azalması, ölüm oranlarını artırmaktadır.

Barlow ve Vissandjee (1999) çalışmalarında 77 gelişmiş ve gelişmekte olan ülkeye ait 1990 yılı yatay kesit verileri ile yaşam beklentisinin belirleyicilerini analiz etmişlerdir. Analiz sonuçlarına göre, kişi başına gelir düzeyindeki artışlar yaşam beklentisini artırırken sağlık harcamalarının yaşam beklentisi üzerinde anlamlı bir etkisine rastlanmamıştır.

Or (2000) sağlık koşullarının belirleyicilerini 21 sanayileşmiş OECD ülkesi için 1970-1992 dönemi verileri ile araştırmıştır. Çalışmada sağlık göstergesi olarak kadın ve erkek erken ölüm oranları kullanılmıştır. Sabit etkiler modeli tahmin sonuçlarına göre, kamu sağlık harcamalarının artması, kadınlarda erken ölümleri azaltmaktadır. Modelden GSYİH değişkeni çıkarıldığında, aynı sonuç erkekler için de geçerli olmaktadır. Yazar bu durumun, doğrusal bağlilık sorunundan kaynaklandığını öne sürmektedir. Çalışmadan elde edilen diğer sonuçlara göre beyaz yakalı çalışan sayısı arttıkça ölüm oranı düşmekte iken, alkol kullanımının artması ölüm oranlarını artırmaktadır.

Kalediene ve Petrauskiene (2000) çalışmalarında 1988-1996 dönemi verileri ile Litvanya'nın 55 bölgesi için yaşam beklentisinin belirleyicilerini araştırmışlardır. Elde edilen Havuzlanmış yatay kesit regresyon analizi sonuçları; kamu sağlık harcamaları, her bin kişi başına düşen doktor sayısı ve hastanelerdeki yatak sayısı gibi sağlık hizmetlerinin beklenen yaşam süresi üzerinde anlamlı bir etkisinin olmadığını göstermektedir.

Messias (2003) çalışmasında 27 Brezilya eyaletine ait 2000 yılı verileri ile kişi başına gelir, gelir dağılımı ve okuryazarlık oranı ile yaşam beklentisi arasındaki ilişkiyi araştırmıştır. Çoklu doğrusal regresyon analizi sonuçlarına göre, kişi başına gelir artışı ve okuryazarlık oranının artması, yaşam beklentisini pozitif yönde etkilerken gelir eşitsizliği ile yaşam beklentisi arasında anlamlı bir ilişki bulunamamıştır. 
Nixon ve Ulmann (2006) çalışmalarında sağlık harcamalarının yaşam beklentisi ve bebek ölümleri üzerindeki etkilerini 15 Avrupa ülkesi için 1980-1995 dönemi verileri ile araştırmışlardır. Sabit etkiler modeli tahmin sonuçları, sağlık harcamalarının bebek ölümlerini güçlü bir şekilde düşürdügünü gösterirken yaşam beklentisi üzerinde beklenen etki görülmemektedir.

Kabir (2008)'in 91 ülkeye ait verilerle yaşam beklentisinin belirleyicilerine yönelik araştırması, beklenenin dışında sonuçlar vermiştir. Buna göre, kişi başına gelir ve kişi başına sağlık harcamalarının yaşam beklentisi üzerinde anlamlı bir etkisi yoktur. Çalışmadan elde edilen diğer sonuçlara göre, doktor sayısının artması yaşam beklentisini artırırken yetersiz beslenme yaşam beklentisini düşürmektedir.

Tüylüoğlu ve Tekin (2009) çalışmalarında 186 ülkeye ait 2003 yılı verileri ile sağlık harcamaları ve ekonomik büyümenin, doğumda yaşam beklentisi üzerindeki etkilerini araştırmışlardır. Yatay kesit regresyon analizi sonuçlarına göre, sağlık harcamalarının artması ve ekonomik büyüme, yaşam beklentisini pozitif yönde etkilemektedir.

Şahin (2018) APEC (Asya Pasifik Ekonomik İş birliği) ülkeleri için doğumda yaşam beklentisinin belirleyicilerini 2000-2013 dönemi verileri ile analiz etmiştir. Panel veri analiz sonuçlarına göre, kişi başına gelir, gıda üretimi ve sağlık harcamalarının artması, yaşam beklentisini pozitif yönde etkilemektedir. Ayrıca işsizliğin ve enflasyonun yaşam beklentisi üzerine etkisi negatiftir.

Yapılan ampirik çalışmalardan elde edilen sonuçlar, yaşam beklentisinin belirleyici üzerinde ortak bir sonuca varılamadığını göstermektedir. Özellikle sağlık harcamalarının toplum sağlığının iyileştirilmesi bağlamında istenen hedefe ulaşıp ulaşmadığı net değildir. Ülkelerin uyguladıkları sağlık sistemlerinin farklılı̆̆ yapılan sağlık harcamalarının etkinlik düzeyini değiștirebilmektedir. Bu durum, heterojen analizleri gerekli kılmaktadır. Mevcut literatürde Türkiye'de gelir eşitsizliğinin ve sağlık harcamalarının sağlık üzerindeki etkilerini araştıran ampirik bir çalışmaya rastlanmamıştır. Bu çalışmanın, Türkiye'nin yaşam beklentisini etkileyen faktörlerin belirlenmesi bağlamında mevcut literatüre katkı sağlayacağı düşünülmektedir.

\section{Yöntem ve Veri Seti}

Türkiye'de gelir dağılımı, sağlık harcamaları ve yaşam beklentisi ilişkisini araştırmak üzere mevcut literatürü takiben kurulan model aşağıdaki gibidir.

$$
L E X_{t}=\beta_{0}+\beta_{1} G I N I_{t}+\beta_{2} G D P_{t}+\beta_{3} H E_{t}+\beta_{4} P H Y_{t}+\varepsilon_{t}
$$

Yukarıdaki eşitlikte $L E X$, doğumda yaşam beklentisini; GINI, Gini katsayısını; $G D P$, kişi başı reel gayrisafi yurtiçi hasılayı (taban yılı 2010); $H E$, sağlık harcamalarının milli gelir içindeki payını ve $P H Y$ ise her 1000 kişi başına düşen doktor sayısını; göstermektedir. Yaşam beklentisi ve GSYIH verileri Dünya Bankası Dünya Kalkınma Göstergeleri veri tabanından, sağlık harcamaları ve doktor sayısı verileri OECD veri tabanından ve gelir dağılımı verisi Solt (2019) 
tarafından hesaplanan Standartlaştırılmış Dünya Gelir Eşitsizliği Veri Tabanı (SWIID)'ndan alınmıştır. Veri seti, yıllık gözlemlerden oluşan ve 1987-2016 dönemini kapsayan zaman serisi biçimindedir.

İlgili dönemde Türkiye' de gelir dağılımı, sağlık harcamaları ve yaşam beklentisinin seyri şekil 1'de yer almaktadır. Bu şekilde görüldüğü üzere Türkiye'de doğumda yaşam beklentisinde 1987-2016 yılları arası sürekli bir artış yaşanmış ve yaşam beklentisi 2016 itibariyle 75,7 yıla yükselmiştir. Aynı zamanda 1995 yılı itibariyle Gini katsayısının düşmeye başladığı başka bir ifade ile gelir dağılımının iyileştiği göze çarpmaktadır. Ancak bu iyileşme, 2013 yılından itibaren yerini bozulmaya bırakmıştır. Aynı dönemde yaşam beklentisi artış hızının da arttığı gözlenmektedir. Öte yandan sağlık harcamalarının milli gelir içindeki payı, dalgalı bir seyir izlemektedir. Aynı dönemde her 1000 kişi başına doktor sayısının da sürekli olarak arttığ1 görülmektedir.

Şekil 1: Modeldeki Değişkenlerin 1987-2016 Dönemi Grafikleri
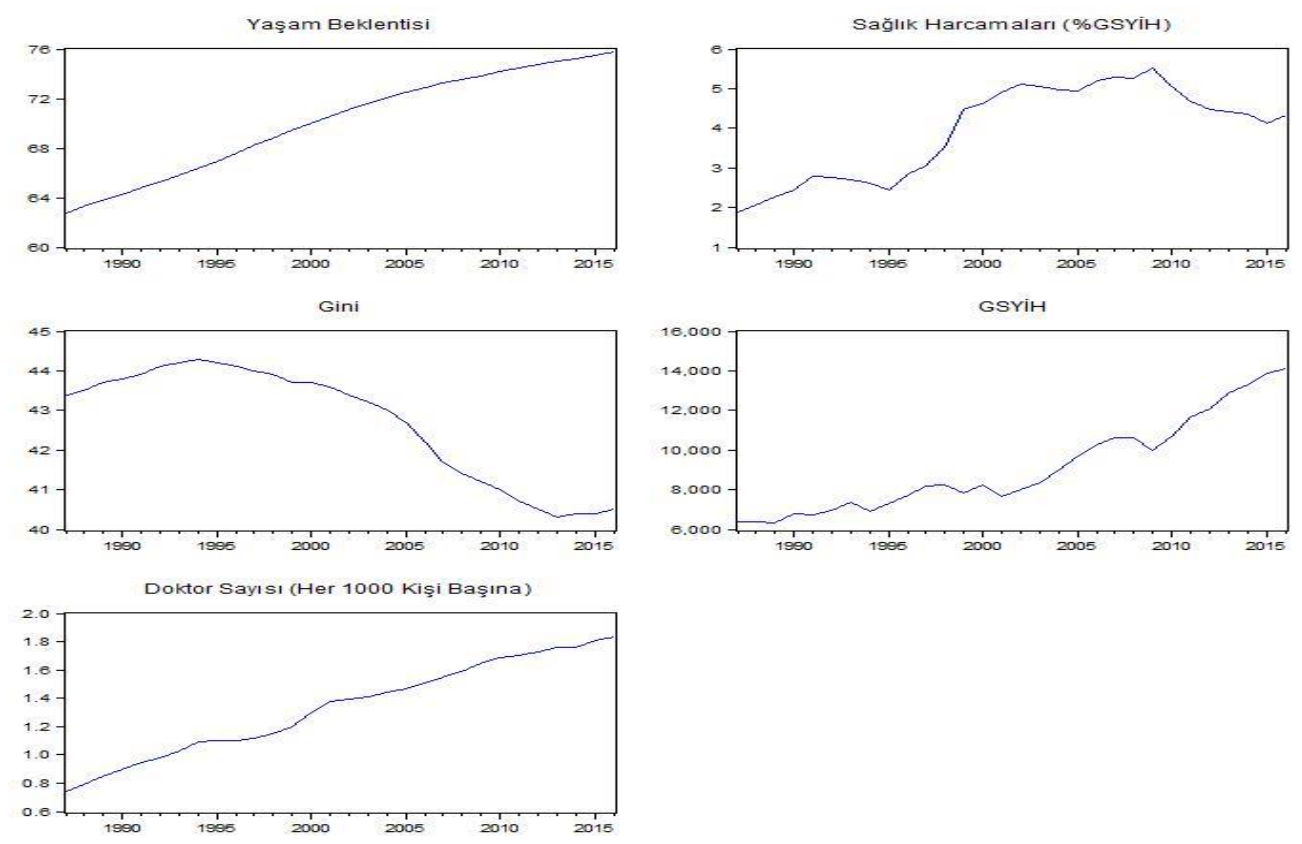

Çalışmada analiz yöntemi olarak Pesaran ve Shin (1998) ve Pesaran vd. (2001) tarafından geliştirilen gecikmesi dağıtılmış otoregresif (ARDL) sınır testi yaklaşımı kullanılmıştır. Bu yöntem, Engle ve Granger (1987) ve Johansen ve Juselius (1990) tarafından geliştirilen eş bütünleşme analiz yöntemlerine kıyasla bazı üstünlüklere sahiptir. Öncelikle Engle-Granger ve Johansen-Juselius eş bütünleşme yöntemleri, tüm serilerin birinci farklarının durağan olmasını gerektirirken; ARDL yöntemi farklı durağanlık düzeylerindeki serilerle eş bütünleşme analizine imkân vermektedir. Ayrıca ARDL yöntemi, düşük gözlem sayısına sahip veri setleri ile analiz yapılırken diğer eş bütünleşme yöntemlerine kıyasla daha doğru sonuçlar alınmasını sağlamaktadır. Son olarak ARDL modeli, dışsal değişkenlerin seçiminde 
daha geniş seçeneklere izin vermektedir. Bu doğrultuda, 1 numaralı denklem çerçevesinde kurulan ARDL modeli aşağıdaki gibidir;

$$
\begin{aligned}
& \Delta \operatorname{LEX}_{t}=\psi+\eta_{0} \mathrm{LEX}_{t-1}+\eta_{1} \mathrm{GINI}_{t-1}+\eta_{2} G D P_{t-1}+\eta_{3} \mathrm{HE}_{t-1}+\eta_{4} \mathrm{PHY}_{t-1}+\sum_{j=1}^{p} \beta_{1 j} \Delta \mathrm{LEX}_{t-j} \\
& +\sum_{j=0}^{q} \beta_{2 j} \Delta \mathrm{GINI}_{t-j}+\sum_{j=0}^{q} \beta_{3 j} \Delta G D P_{t-j}+\sum_{j=0}^{q} \beta_{4 j} \Delta \mathrm{HE}_{\mathrm{t}-\mathrm{j}}+\sum_{\mathrm{j}=0}^{\mathrm{q}} \beta_{4 \mathrm{j}} \Delta \mathrm{PHY}_{t-j}+\varepsilon_{\mathrm{t}}
\end{aligned}
$$

ARDL tahmini sonrasında değişkenler arasındaki uzun dönemli ilişki, sınır testi ile analiz edilecektir. Sınır testi yöntemi, "eş bütünleşme yoktur" hipotezinin F istatistiği ile test edilmesine dayanmaktadır. Hesaplanan F istatistiği üst sınır kritik değerini aşıyorsa, eş bütünleşme yoktur hipotezi reddedilir. Bu sonuç, söz konusu değişkenler arasında uzun dönemli bir ilişkinin varlığına işaret etmektedir. Eş bütünleşme ilişkisinin varlığı araştırıldıktan sonra aşağıdaki denklemler çerçevesinde hata düzeltme modeli kurulacaktır;

$$
\begin{aligned}
& E C T_{t}=L E X_{t}-\beta_{0}-\beta_{1} G I N I_{t}-\beta_{2} G D P_{t}-\beta_{3} H E_{t}-\beta_{4} P H Y_{t} \\
& \Delta L E X_{t}=\gamma_{0}+\sum_{i=1}^{n} \gamma_{1 i} \Delta L E X_{t-i}+\sum_{i=0}^{q} \gamma_{2 i} \Delta G I N I_{t-i}+\sum_{i=0}^{r} \gamma_{3 i} \Delta G D P_{t-i} \\
& +\sum_{i=0}^{z} \gamma_{4 i} \Delta H E_{t-i}+\sum_{i=0}^{v} \gamma_{5 i} \Delta P H Y_{t-i}+\delta E C T_{t-1}+\varepsilon_{t}
\end{aligned}
$$

Hata düzeltme modeli tahmin sonuçlarına göre hata düzeltme teriminin gecikmeli değerinin $\left(E C T_{t-1}\right)$ katsayısının negatif ve anlamlı olması beklenmektedir. Değişkenler arasındaki bu uzun dönemli dengeden sapmaların yaklaşık olarak kaç period sonra düzeleceğini göstermektedir.

\subsection{Ampirik Bulgular ve Tartışma}

Analizde öncelikle değişkenlerin durağanlık seviyeleri Kwiatkovski vd. (1992) tarafından geliştirilen KPSS birim kök testi ile araştırılacaktır. Bu yöntem 100 gözlemden düşük zaman boyutlarında diğer geleneksel birim kök testlerine göre daha doğru sonuçlar vermektedir (Shin ve Schimidt, 1992).

Değişkenlerin durağanlığına ilişkin KPSS birim kök testi sonuçları tablo 2'de verilmiştir. Değişkenlerin durağanlık analizinde tüm değişkenler için sabit ve trend dikkate alınmış, değişkenlerin fark değerlerinde ise yalnızca sabit dikkate alınmıştır. Newey ve West (1994) metodu ile belirlenen bant genişliği sayısı, tabloda parantez içerinde verilmiştir. Birim kök testi sonuçlarına göre, tüm değişkenler birim kök içermektedir ve değişkenlerin birinci farkları durağandır. Bu durum, ilgili değişkenlerin durağanlık derecelerinin ARDL eş bütünleşme testi için uygun olduğunu göstermektedir. 
Ergül HALİSÇELİK, Ali ACARAVCI, Arif Sezer GÜZEL

Tablo 2: KPSS Birim Kök Testi Sonuçları

\begin{tabular}{|l|l|c|c|}
\hline Değișkenler & Düzey & 1.Fark & Sonuç \\
\hline LEX & $0,1861^{* *}(4)$ & $0,1406(4)$ & $I(1)$ \\
\hline GINI & $0,1693^{* *}(4)$ & $0,3375(4)$ & $I(1)$ \\
\hline GDP & $0,1658^{* *}(3)$ & $0,1701(3)$ & $I(1)$ \\
\hline HE & $0,1644^{* *}(4)$ & $0,3368(3)$ & $I(1)$ \\
\hline PHY & $0,1966^{* *}(3)$ & $0,0760(4)$ & $I(1)$ \\
\hline \%5 Kritik Değer & 0,1460 & 0,4630 & \\
\hline
\end{tabular}

Değişkenler arasındaki uzun dönemli ilişkilerin analizi için tahmin edilen ARDL modeli tahmin sonuçları tablo 3'de verilmiştir. ARDL modeli tahmininde maksimum gecikme düzeyi 3 olarak belirlenmiş ve optimal gecikme seviyesi Schwarz bilgi kriterine göre belirlenmiştir. $\mathrm{Bu}$ gecikme düzeyinde yapılan tanı testleri; otokorelasyon, değişken varyans ve model tanımlama sorunlarının olmadığını ve hata terimlerinin normal dağıldığını göstermektedir. Eş bütünleşme ilişkisinin varlığını analiz etmek üzere yapılan sınır testi analizi sonuçları tablo 4'teki gibidir.

Tablo 3: ARDL (2, 1, 3, 3, 0) Tahmin Sonuçları

\begin{tabular}{|c|c|c|}
\hline Değişkenler & Katsayı & $t$ istatistiği \\
\hline LEX(-1) & 2,0453 & $64,409 * * *$ \\
\hline LEX(-2) & $-1,0966$ & $-31,460 * * *$ \\
\hline GINI & $-0,0152$ & $-3,3082 * * *$ \\
\hline GINI(-1) & 0,0070 & 1,6399 \\
\hline GDP & 0,0001 & 0,4128 \\
\hline GDP(-1) & 0,0002 & 0,9225 \\
\hline GDP(-2) & 0,0007 & $2,3986 * *$ \\
\hline GDP(-3) & 0,0010 & $3,1383 * * *$ \\
\hline HE & 0,0002 & 0,8584 \\
\hline PHY & 0,0013 & 1,4428 \\
\hline PHY(-1) & 0,0016 & 1,1151 \\
\hline PHY(-2) & 0,0013 & 0,9647 \\
\hline PHY(-3) & 0,0040 & $3,7412 * * *$ \\
\hline C & 0,2251 & $6,0580 * * *$ \\
\hline$X_{L M}^{2}$ & \multicolumn{2}{|c|}{$0,1735(0,785)$} \\
\hline$X_{H E T}^{2}$ & \multicolumn{2}{|c|}{$10,602(0,644)$} \\
\hline JB & \multicolumn{2}{|c|}{$1,2360(0,539)$} \\
\hline Ramsey-Reset (F) & \multicolumn{2}{|c|}{$1,0271(0,325)$} \\
\hline
\end{tabular}

Sınır testi analiz sonuçlarına göre hesaplanan F istatistiğinin değeri, \%5 kritik değerin üzerindedir. Buna göre "uzun dönemli ilişki yoktur" hipotezi $\% 5$ anlamlılık düzeyinde güçlü bir şekilde reddedildiğinden; değişkenler arasında anlamlı bir eş bütünleşme ilişkisi mevcut olduğu sonucuna ulaşılmıştır. 
Tablo 4: Sinır Testi Analizi

\begin{tabular}{|l|l|l|l|}
\hline $\mathbf{k}$ & F istatistiği & \%5 alt sinır & \%5 üst sinır \\
\hline 4 & 74,0500 & 2,86 & 4,01 \\
\hline
\end{tabular}

Tablo 5'te modelin uzun dönem katsayıları yer almaktadır. Gini katsayısındaki artışların yaşam beklentisi üzerindeki etkisi, istatistiksel olarak $\% 1$ anlamlılık düzeyinde negatif yönlüdür. Burada Gini katsayısının yükselmesi, daha adaletsiz bir gelir dağılımı anlamına geldiğinden; gelir dağılımında adaletin sağlanması, Türkiye'de yaşam beklentisini yükseltmektedir. Bu sonuç, Rodgers (1979) ile Wilkinson (1992)'ın kanıtlarını destekler niteliktedir. Buna göre gelir dağılımında adaletin sağlanmasının daha sağlıklı bir topluma ulaşmada önemli bir araç olduğu görülmektedir.

Barlow ve Vissandjee (1999) ve Şahin (2018)'in elde ettikleri sonuçlara paralel olarak kişi başı gelirin artması, yaşam beklentisini istatistiksel olarak \%1 anlamlılık düzeyinde pozitif olarak etkilemektedir. Sağlık harcamaları ile yaşam beklentisi arasında ise anlamlı bir ilişkiye rastlanılmamıştır. Bu sonuç Barlow ve Vissandjee (1999), Kalediene ve Petrauskiene (2000) ve Kabir (2008)'in çalışmalarını desteklemektedir. Öte yandan Tüylüoğlu ve Tekin (2009) ile Şahin (2018)'in sağlık harcamaları ile yaşam beklentisi arasında elde ettikleri pozitif ilişkiye rastlanmamıştır.

Yapılan çalışmalarda örneklem değiştikçe sağlık harcamalarının sağlık çıktısı yaratmadaki etkinliğinin farklılaştığı gözlenmektedir. Türkiye'de bu sonucun ortaya çıkmaması, sağlık harcamaları yoluyla daha sağlıklı bir toplum hedefine ulaşılamadığını göstermektedir. Modele kontrol değişken olarak dâhil edilen doktor sayısı değişkeni de yaşam beklentisini pozitif yönde etkilemektedir. Kalediene ve Petrauskiene (2000) ve Kabir (2008)'in bulgularını destekler nitelikte olan bu sonuç, yetişmiş sağlık personeli sayısının artmasının yaşam beklentisini artırdığını göstermektedir.

Tablo 5: Uzun Dönem Katsayıları

\begin{tabular}{|l|l|l|}
\hline Değişkenler & Katsayı & t istatistiği \\
\hline GINI & $-0,1597$ & $-3,1087 * * *$ \\
\hline GDP & 0,0443 & $6,5129 * * *$ \\
\hline HE & 0,0044 & 0,9784 \\
\hline PHY & 0,1623 & $28,5484 * * *$ \\
\hline C & 4,3881 & $18,6964 * * *$ \\
\hline
\end{tabular}

3 ve 4 numaralı denklemler çerçevesinde tahmin edilen hata düzeltme modeli sonuçları tablo 6'te verilmiştir. Buna göre hata teriminin gecikmeli değerinin katsayısı, negatiftir ve \%1 düzeyinde anlamlıdır. Bu katsayının düşük olması, dengeden sapmaların yavaşça ortadan kalktığını göstermektedir. 
Tablo 6: Hata Düzeltme Modeli

\begin{tabular}{|l|c|c|}
\hline Değişkenler & Katsayı & t istatistiği \\
\hline D(LEX(-1)) & 1,0966 & $31,4602^{* * *}$ \\
\hline D(GINI) & $-0,0152$ & $-3,3082^{* * *}$ \\
\hline D(GDP) & 0,0001 & 0,4128 \\
\hline D(GDP(-1)) & $-0,0007$ & $-2,3986^{* *}$ \\
\hline D(GDP(-2)) & $-0,0010$ & $-3,1383^{* * *}$ \\
\hline D(HE) & 0,0002 & 0,8584 \\
\hline D(PHY) & 0,0013 & 1,4428 \\
\hline D(PHY(-1)) & $-0,0013$ & $-0,9647$ \\
\hline D(PHY(-2)) & $-0,0040$ & $-3,7412^{* * *}$ \\
\hline ECT(-1) & $-0,0513$ & $-6,3159^{* * *}$ \\
\hline
\end{tabular}

Modelde hesaplanan uzun dönem katsayıların, 1987-2016 dönemleri arasında istikrarlılığı Brown vd. (1975) tarafindan geliştirilen CUSUM ve CUSUM $^{2}$ testleri ile araştırılmıştır ve sonuçlar şekil 2'de verilmiştir. CUSUM ve CUSUM ${ }^{2}$ testleri sonuçlarına göre tahmin edilen parametreler $\% 5$ anlamlılık düzeyinde istikrarlı olduğunu görülmektedir.

Şekil 2: CUSUM ve CUSUM² Testi Sonuçları
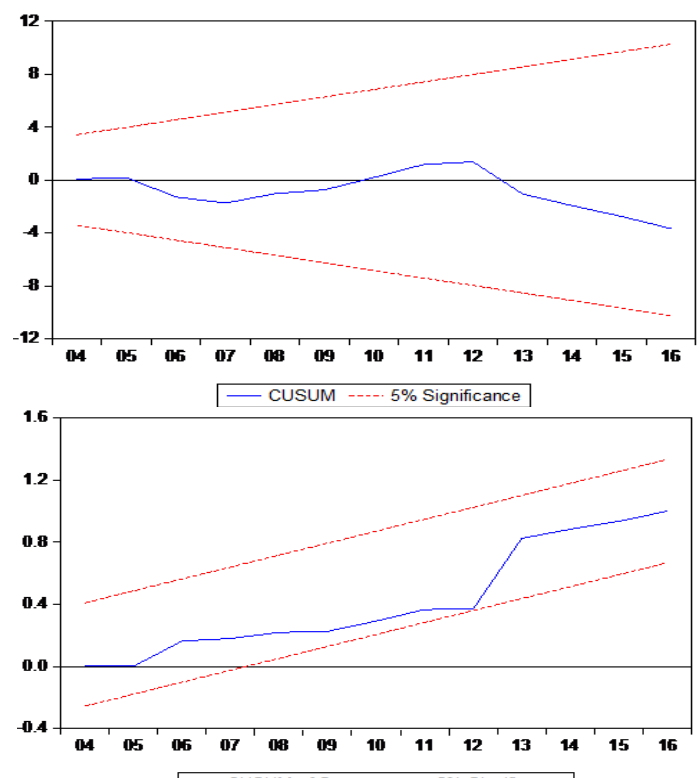

\section{Sonuç}

Sağlık, toplumsal refahın en önemli göstergelerinden biri olmakla birlikte daha iyi yaşam standartlarına ulaşmada önemli bir araçtır. Ekonomik gelişmişliğin sağlanması için gerekli olan insan sermayesinin oluşumunda öncelikle sağlıklı bir topluma ihtiyaç vardır. Ekonomik gelişme ve sağlıklı bir toplumun oluşması, iki 
yönlü bir süreci ifade etmektedir. Daha sağlıklı bireyler, daha yüksek bir gelir düzeyine ulaşmanın önünü açabilecektir. Ancak bu süreçte toplumun genelinin sağlık koşullarının iyileşmesi için, toplumun yoksul kesiminin yaratılan gelir artışından aldığı payın artması gerekmektedir. Yoksulların refahının iyileştirilmesi; onların daha insani koşullarda çalışmaları, daha iyi beslenmeleri ve sağlık hizmetlerine daha kolay ulaşabilmelerini sağlayabilecektir. Böylece toplumun geneli için daha uzun ve sağlıklı yaşam koşulları oluşabilecektir.

Bu çalışmada Türkiye'de gelir dağılımı ve sağlık harcamalarının doğumda yaşam beklentisi üzerindeki etkileri ARDL modeli ve sınır testi analiz yöntemiyle araştırılmıştır. Analiz sonuçlarına göre gelir dağılımında adaletsizliğin azalması, doğumda yaşam beklentisini artırmaktadır. Sağlık harcamalarının milli gelir içerisindeki payının artması ile yaşam beklentisi arasında ise anlamlı bir ilişkiye rastlanmamıştır. Diğer yandan modele kontrol değişkenler olarak dâhil edilen kişi başına reel gelir ile her bin kişi başına doktor sayısı değişkenlerinin, yaşam beklentisini pozitif yönde etkilediği görülmüştür.

Çalışmadan elde edilen sonuçlara değerlendirildiğinde, yoksul kesimin refahının artmasının yaşam beklentisi üzerinde kamu sağlık harcamalarına kıyasla daha etkin sonuçlar doğurduğu görülmektedir. Bu bağlamda daha sağlıklı bir toplum için en etkin politikanın ülkedeki yoksulluğu azaltma olduğu söylenebilir. Kişi başına gelir artışının yanında elde edilen gelirin tabana yayılması ile toplumda daha uzun ve sağlıklı bir yaşamın önü açılabilecektir.

\section{Kaynakça}

Barlow, R. ve Vissandjee, B. (1999). Determinants of national life expectancy. Canadian Journal of Development Studies/Revue canadienne d'études du développement, 20(1), 9-29.

Brown, R. L., Durbin, J. ve Evans, J. M. (1975). Techniques for testing the constancy of regression relationships over time. Journal of the Royal Statistical Society: Series B (Methodological), 37(2), 149-163.

Çelik, Y. (2011). Türkiye sağlık harcamalarının analizi ve sağlık harcama düzeyinin uygunluğunun değerlendirilmesi. SGD-Sosyal Güvenlik Dergisi, 1(1), 62-81.

Deaton, A. (2003). Health, inequality, and economic development. Journal of economic literature, 41(1), 113-158.

Engle, R. F. ve Granger, C. W. (1987). Co-integration and error correction: representation, estimation, and testing. Econometrica: journal of the Econometric Society, 55(2), 251-276.

Johansen, S. ve Juselius, K. (1990). Maximum likelihood estimation and inference on cointegration - with applications to the demand for money. Oxford Bulletin of Economics and statistics, 52(2), 169-210. 
Judge, K. (1995). Income distribution and life expectancy: a critical appraisal. Bmj, 311(7015), 1282-1285.

Kabir, M. (2008). Determinants of life expectancy in developing countries. The journal of Developing Areas, 41(2), 185-204.

Kalediene, R. ve Petrauskiene, J. (2000). Regional life expectancy patterns in Lithuania. The European Journal of Public Health, 10(2), 101-104.

Kawachi, I., Kennedy, B. P., Lochner, K. ve Prothrow-Stith, D. (1997). Social capital, income inequality, and mortality. American journal of public health, 87(9), 1491-1498.

Kwiatkowski, D., Phillips, P. C., Schmidt, P. ve Shin, Y. (1992). Testing the null hypothesis of stationarity against the alternative of a unit root: How sure are we that economic time series have a unit root?. Journal of econometrics, 54(1-3), 159-178.

Messias, E. (2003). Income inequality, illiteracy rate, and life expectancy in Brazil. American Journal of Public Health, 93(8), 1294-1296.

Newey, W. K. ve West, K. D. (1994). Automatic lag selection in covariance matrix estimation. The Review of Economic Studies, 61(4), 631-653.

Nixon, J. ve Ulmann, P. (2006). The relationship between health care expenditure and health outcomes. The European Journal of Health Economics, 7(1), 7-18.

Or, Z. (2000). Determinants of health outcomes in industrialized countries: a pooled, cross-country, time-series analysis. OECD Economic Studies, 30, 5378.

Pesaran, M. H. ve Shin, Y. (1998). An autoregressive distributed-lag modelling approach to cointegration analysis. Econometric Society Monographs, 31, 371413.

Pesaran, M. H., Shin, Y. ve Smith, R. J. (2001). Bounds testing approaches to the analysis of level relationships. Journal of applied econometrics, 16(3), 289-326.

Preston, S. H. (1975). The changing relation between mortality and level of economic development. Population studies, 29(2), 231-248.

Rodgers, G. B. (1979). Income and inequality as determinants of mortality: an international cross-section analysis. Population studies, 33(2), 343-351.

Saunders, P. (1996). Poverty, income distribution and health: an Australian study (Vol. 128). University of New South Wales.

Sen, A. (1999). Health in development. Bulletin of the World Health Organization, 77(8), 619.

Shin, Y. ve Schmidt, P. (1992). The KPSS stationarity test as a unit root test. Economics Letters, 38(4), 387-392. 
Solt, F. 2019. Measuring Income Inequality Across Countries and Over Time: The Standardized World Income Inequality Database. SWIID Version 8.1, May 2019.

Şahin, D. (2018). Doğumda Yaşam Beklentisinin Belirleyicilerinin Analizi: APEC Ülkeleri Örneği. Ömer Halisdemir Üniversitesi İktisadi ve İdari Bilimler Fakültesi Dergisi, 11(1), 1-7.

Tüylüoğlu, Ş. ve Tekin, M. (2009). Gelir Düzeyi ve Sağlık Harcamalarının Beklenen Yaşam Süresi ve Bebek Ölüm Oranı Üzerindeki Etkileri. Çukurova Üniversitesi İktisadi ve İdari Bilimler Fakültesi Dergisi, 13(1), 1-31.

Well, D. N. (2007). Accounting for the effect of health on economic growth. The quarterly journal of economics, 122(3), 1265-1306.

Wilkinson, R. G. (1992). Income distribution and life expectancy. BMJ: British Medical Journal, 304(6820), 165.

Wilkinson, R. G. (1992). National mortality rates: the impact of inequality?. American Journal of Public Health, 82(8), 1082-1084. 